\title{
Implications of Anti-Ro/Sjögren's Syndrome A Antigen Autoantibody in Normal Sera for Autoimmunity
}

\author{
Kimberley K. Gaither, ${ }^{\star \ddagger}$ Owen F. Fox, ${ }^{\ddagger}$ Hajime Yamagata, ${ }^{\ddagger}$ Mark J. Mamula, ${ }^{\star \ddagger}$ Morris Reichlin, ${ }^{\star \star}$ and John B. Harley ${ }^{\star * 5}$ \\ ${ }^{*}$ Departments of Medicine and Microbiology, University of Oklahoma Health Sciences Center; ${ }^{\ddagger}$ The Arthritis and Immunology Program, \\ Oklahoma Medical Research Foundation; and ${ }^{\S}$ Veterans Administration Medical Center, Oklahoma City, Oklahoma 73104
}

\begin{abstract}
We have applied a sensitive assay to analyze lupus and Sjögren's syndrome autoantibodies in $\mathbf{4 0}$ normal sera. Seven of these bound Ro/Sjögren's syndrome A antigen (SSA). Although this binding was 1,000-fold lower than the highest anti-Ro/SSA level measured from patients, it was inhibited by human Ro/SSA. Positive normal serum-bound Ro/SSA in Western immunoblots and binding activity was demonstrated in the $F\left(a^{\prime}\right)_{2}$ fragment of IgG. Affinity purification of normal anti-Ro/SSA IgG increased the specific anti-Ro/SSA binding by $>17$-fold. This purified antibody formed a Ro/SSA precipitin and had a relative affinity for Ro/SSA identical to that of Ro/SSA precipitin-positive patients. These data demonstrate that the anti-Ro/SSA present in healthy normal donors is true autoantibody.

Anti-La/Sjögren's syndrome B antigen (SSB) autoantibodies were found in 3 of the $\mathbf{4 0}$ normal sera, while none bound nuclear ribonucleoprotein (Sm). Finding low levels of anti-Ro/SSA and anti-La/SSB among normals may indicate that anti-Ro/SSA and anti-La/SSB occur in disease by enhancement of a preexisting immune response.
\end{abstract}

\section{Introduction}

Since systemic lupus erythematosus (SLE) and Sjögren's syndrome (SS) ${ }^{1}$ are diseases acquired by those previously in good health, the characterization of autoimmunity in normals may define how the transition to disease occurs. Autoantibody to Ro/Sjögren's syndrome A antigen (SSA) and La/Sjögren's syndrome B antigen (SSB) commonly occur in patients with SLE and SS (1-3). The presence of anti-Ro/SSA can be associated with several patterns of disease expression, including nephritis (4), complement component C2 deficiency (5), and photosensitive cutaneous lupus lesions (6). This antibody has also been found in mothers of infants with either cutaneous neonatal lupus or congenital complete heart block $(7,8)$, and $0.1 \%$ of hospitalized patients (9), as well as some relatives of patients with autoimmune connective tissue disease $(10,11)$.

Address correspondence to Dr. Harley, Department of Medicine, U. of Oklahoma Health Sciences Center, P.O. Box 26901, Oklahoma City, OK 73190.

Received for publication 21 August 1986 and in revised form 29 October 1986.

1. Abbreviations used in this paper: CIE, counterimmunoelectrophoresis; nRNP, nuclear ribonucleoprotein; SS, Sjögren's syndrome; SSA and SSB, Sjögren's syndrome A and B antigens.

J. Clin. Invest.

(c) The American Society for Clinical Investigation, Inc.

$0021-9738 / 87 / 03 / 0841 / 06 \$ 1.00$

Volume 79, March 1987, 841-846
Ro/SSA is a RNA-protein complex composed of a 60,000 $D$ peptide noncovalently associated with certain small uridinerich RNAs. In man, there are four RNAs that are associated with the Ro/SSA peptide (12). The antigenicity is found in at least the peptide since RNAse digestion does not alter its reactivity with anti-Ro/SSA antibody and since the peptide alone reacts with anti-Ro/SSA autoimmune sera in immunoblots (13, 14). The RNA is termed Y RNA (cytoplasmic RNA) to signify that it is found in the cytoplasm in agreement with early work using autoimmune sera $(13,15)$, but more recent workers have claimed that the antigen is found in the nucleus (16). The role of this RNA-protein in cellular metabolism is not known. Nor is it understood why Ro/SSA is a relatively common autoantigen in man, much less what the factors are that lead this autoantibody in some individuals to be associated with particular disease states or clinical manifestations, while others with anti-Ro/SSA are asymptomatic.

Traditionally, anti-Ro/SSA has been detected by Ouchterlony immunodiffusion using tissue extracts as the antigen source (13). With the purification of Ro/SSA, much more sensitive solidphase assays have become feasible (14). We have evaluated the normal sera with high binding levels to determine if they do indeed have anti-Ro/SSA autoantibody and contrasted their Ro/ SSA binding to that of La/SSB (17) and nuclear ribonucleoprotein (nRNP)(Sm).

\section{Methods}

Sample collection. Serum samples from 13 patients with Ro/SSA precipitins and 40 normal donors were collected and stored at $-20^{\circ} \mathrm{C}$. Normal donors included lab workers, physicians, secretaries, and medical students whose mean age was 32.7 yr with a range of 22 to 54 yr. Subdivisions according to race and sex were as follows: 38 , caucasian, 1 , negroid, 1 , oriental, 26 female, and 16 male.

Antigen purification. Ro/SSA and La/SSB were purified from calf thymus and human spleen extracts as described $(14,17)$. Parallel technology was used to purify the $\mathrm{nRNP}(\mathrm{Sm})$ antigen using relatively monospecific anti-nRNP IgG to construct an affinity column. Since anti-nRNP purified the $U_{1}$ particle, which contains both $\mathrm{nRNP}$ and Sm activities, the resulting preparation has been designated $\mathrm{nRNP}(\mathrm{Sm})$.

Enzyme-linked immunosorbent assay (ELISA). A solid-phase assay similar to that described previously $(14,18)$ was used to detect antibody binding. U-vinyl microtiter plates (Costar, Cambridge, MA) were coated overnight with purified bovine Ro/SSA, La/SSB, or nRNP(Sm) at 1-5 $\mu \mathrm{g} / \mathrm{ml}$ in carbonate-coating buffer, $\mathrm{pH}$ 9.6. Remaining protein binding sites in the wells were blocked with $0.1 \%$ bovine serum albumin (BSA) in $0.02 \mathrm{M}$ phosphate-buffered saline (PBS), $\mathrm{pH}$ 7.4. The plates were washed thrice with $0.05 \%$ Tween in PBS (Tween-PBS). Appropriate serum or antibody dilutions in PBS with $0.1 \%$ BSA and $0.05 \%$ Tween (diluent) were added to the plate and incubated 16-18 h. After a second TweenPBS wash, 1:1,000 dilution of affinity-purified goat anti-human IgG conjugated to alkaline phosphatase (Sigma Chemical Co., St. Louis, MO) in diluent was added and allowed to incubate 6-8 h. All incubations were made at $4^{\circ} \mathrm{C}$. The plates were washed five times with Tween-PBS 
and developed at room temperature with $p$-nitrophenylphosphate (Sigma Chemical Co.). Optical densities were read at $405 \mathrm{~nm}$ with a MR580 Microelisa Autoreader (Dynatec Laboratories, Alexandria, VA). Antibody binding was expressed as units of anti-Ro/SSA activity, where $1 \mathrm{U}$ was equal to the optical change observed in a $10^{-7}$ dilution of an anti-Ro/ SSA precipitin-positive patient serum. Affinity purification of anti-Ro/ SSA (18) and anti-nRNP showed that in each case $1 \mathrm{U}$ of autoantibody activity was between 180 and $230 \mathrm{pg}$ of the purified autoantibody.

All serum samples were also preincubated with $10 \mu \mathrm{g} / \mathrm{ml}$ purified bovine or human autoantigen for $4 \mathrm{~h}$ at room temperature before being added to the Ro/SSA-coated plate. Specific binding activity is reported as the units of anti-Ro/SSA inhibited by purified antigen. Affinity binding curves of anti-Ro/SSA were determined by inhibiting antibody binding with increasing concentrations of Ro/SSA antigen.

Western blot. Polyacrylamide gel electrophoresis was performed under reducing conditions where Ro/SSA was boiled in 5\% $\beta, 2$-mercaptoethanol and $2 \%$ sodium dodecyl sulfate (SDS) and electrophoresed in a $10 \%$ polyacrylamide gel with $0.1 \%$ SDS (14). Ro/SSA was transferred electrophoretically to nitrocellulose paper (19) after which the sheets were blocked for $1 \mathrm{~h}$ at $37^{\circ} \mathrm{C}$ with $3 \% \mathrm{BSA}$. The nitrocellulose strips were washed and incubated with serum dilutions for $6 \mathrm{~h}$ at $4^{\circ} \mathrm{C}$. After a second wash, the strips were incubated in 1:300 dilution of anti-human IgG conjugated to alkaline phosphatase (Sigma Chemical Co.) overnight at $4^{\circ} \mathrm{C}$. The strips were washed and developed with $\beta$-napthyl acid phosphate (20).

$F\left(a b^{\prime}\right)_{2}$ purification. Sera from 13 of the 40 normal donors were collected $18 \mathrm{mo}$ after the initial sampling along with plasma from an antiRo/SSA-positive patient. IgG was isolated from serum by DE52 chromotography (Whatman Chemical Separation, Inc., Clifton, NJ) and digested with pepsin $(21) . F\left(a b^{\prime}\right)_{2}$ fragments were purified by passage through Sephadex G-100 (Pharmacia Fine Chemicals, Piscataway, NJ). The ensuing fractions were coated on a U-vinyl plate and tested for purity with goat anti-human $\mathrm{F}\left(\mathrm{ab}^{\prime}\right)_{2}$ and $\mathrm{Fc}$ conjugated to peroxidase (Cappell Laboratories, Cochranville, PA) using 0 -phenylenediamine as the indicator substrate. All samples with evidence of $\mathrm{Fc}$ contamination were passed through a Staphylococcus protein A Sepharose 4B column (Pharmacia Fine Chemicals), which successfully removed all remaining Fc reactivity.

Anti-Ro/SSA purification. Purified Ro/SSA that showed a single band in an SDS-polyacrylamide gel was coupled by $\mathrm{CNBr}$ activation to Sepharose-4B according to the manufacturer's instructions (Pharmacia Fine Chemicals). Plasma from an anti-Ro/SSA-positive normal donor and patient were passed through the affinity column. Bound immunoglobulin was eluted with $3 \mathrm{M} \mathrm{MgCl}_{2}$ and dialyzed into $0.02 \mathrm{M}$ Tris- $\mathrm{HCl}$, pH 7.3. Anti-Ro/SSA activity was evaluated by ELISA as described above and counterimmunoelectrophoresis (CIE) as described by Wasicek and Reichlin (4).

Autoantibody screen. All available normal sera from the original $\mathbf{4 0}$ donors were tested for antinuclear antibodies by indirect immunofluorescence on HEp-2 cells and mouse kidney substrate and for anti-native DNA on Crithidia lucilliae (22). Anti-single-stranded DNA activity was detected by radioimmunoassay (Farr Technique) and rheumatoid factor was assayed by latex agglutination.

HLA typing. Histocompatability antigens were determined by the microcytotoxicity test using University of California, Los Angeles HLA and DR typing trays (Lamda One; Los Angeles, CA).

Data analysis. Unless otherwise stated, means are presented as the anti $\log _{10}$ of the $\log _{10}$ average of the original data. Fisher's exact test is used to compare categorical data.

\section{Results}

Anti-Ro/SSA antibody levels were assayed by ELISA in sera from 13 patients with precipitating levels of anti-Ro/SSA and 40 normal donors. Patients with anti-Ro/SSA precipitins had between 419,000 and $17,309,000 \mathrm{U}$ of antibody activity specific for Ro/SSA, with an average of 6,022,470 $U$ (Table I). AntiRo/SSA antibody activity in normal sera was $\sim 1,000$-fold lower
Table I. Specific Units of Anti-Ro/SSA Activity in Precipitation-positive Anti-Ro/SSA SLE Patients

\begin{tabular}{llllll}
\hline $\begin{array}{l}\text { Patient } \\
\text { no. }\end{array}$ & $\begin{array}{l}\text { Units of } \\
\text { specific } \\
\text { binding* }\end{array}$ & Inhibition & $\begin{array}{l}\text { Patient } \\
\text { no. }\end{array}$ & $\begin{array}{l}\text { Units of } \\
\text { specific } \\
\text { binding }\end{array}$ & Inhibition \\
\hline & & $\%$ & & & $\%$ \\
1 & $15,815,800$ & 91 & 8 & $7,028,010$ & 99 \\
2 & $3,944,850$ & 91 & 9 & 419,270 & 77 \\
3 & $1,153,000$ & 91 & 10 & $1,323,000$ & 98 \\
4 & $7,701,650$ & 95 & 11 & $3,700,550$ & 97 \\
5 & $11,492,700$ & 87 & 12 & $6,694,080$ & 96 \\
6 & $17,309,000$ & 95 & 13 & $1,173,000$ & 85 \\
7 & 537,230 & 62 & & & \\
\end{tabular}

ELISA was used to measure anti-Ro/SSA in sera from patients with immunoprecipitating levels of autoantibody.

* Arbitrary expression of anti-Ro/SSA activity, where $1 \mathrm{U}$ is equal to the optical density change in a $10^{-7}$ dilution of an anti-Ro/SSA precipitin-positive serum standard. The anti-Ro/SSA specific binding is expressed as the units of anti-Ro/SSA binding activity per milliliter of serum that is inhibited by $10 \mu \mathrm{g} / \mathrm{ml} \mathrm{Ro/SSA}$.

than patient sera and in most of these was not significantly inhibited by purified Ro/SSA. The log average specific binding was 2,484 anti-Ro/SSA units (Table II). 7 of the 40 normal sera

Table II. Units of Anti-Ro/SSA Activity in Normal Human Serum Donors

\begin{tabular}{|c|c|c|c|c|c|c|c|}
\hline \multirow{3}{*}{$\begin{array}{l}\text { Donor } \\
\text { no. }\end{array}$} & \multirow{3}{*}{$\begin{array}{l}\text { Units of } \\
\text { specific } \\
\text { binding }\end{array}$} & \multicolumn{2}{|c|}{ Inhibition } & \multirow{3}{*}{$\begin{array}{l}\text { Donor } \\
\text { no. }\end{array}$} & \multirow{3}{*}{$\begin{array}{l}\text { Units of } \\
\text { specific } \\
\text { binding }\end{array}$} & \multicolumn{2}{|c|}{ Inhibition } \\
\hline & & Bovine & Human & & & Bovine & Human \\
\hline & & Ro/SSA & Ro/SSA & & & Ro/SSA & Ro/SSA \\
\hline & & $\%$ & $\%$ & & & $\%$ & $\%$ \\
\hline 1 & 1,565 & 35 & & 21 & $17,095^{*}$ & 81 & 68 \\
\hline 2 & 2,204 & 44 & & 22 & $12,572^{*}$ & 85 & 92 \\
\hline 3 & 2,389 & 33 & & 23 & 2,495 & 28 & \\
\hline 4 & $16,686^{*}$ & 54 & 69 & 24 & 2,036 & 33 & \\
\hline 5 & 1,966 & 42 & & 25 & $23,690^{*}$ & 88 & 66 \\
\hline 6 & 3,411 & 41 & & 26 & 3,460 & 50 & \\
\hline 7 & 1,587 & 39 & & 27 & 1,041 & 30 & \\
\hline 8 & 2,585 & 46 & & 28 & 1,029 & 41 & \\
\hline 9 & 3,553 & 55 & & 29 & 1,277 & 15 & \\
\hline 10 & 122 & 3 & 44 & 30 & 1,508 & 33 & \\
\hline 11 & 1,117 & 37 & & 31 & 1,357 & 41 & \\
\hline 12 & 1,785 & 27 & & 32 & 4,195 & 46 & \\
\hline 13 & 664 & 29 & 0 & 33 & 3,515 & 52 & \\
\hline 14 & $6,547^{*}$ & 52 & 72 & 34 & 3,824 & 22 & \\
\hline 15 & 1,643 & 52 & & 35 & 587 & 19 & 53 \\
\hline 16 & 448 & 11 & & 36 & 1,122 & 55 & \\
\hline 17 & 2,353 & 34 & & 37 & $5,524^{*}$ & 54 & 75 \\
\hline 18 & 5,156 & 29 & & 38 & $10,819^{*}$ & 84 & 79 \\
\hline 19 & 2,981 & 46 & & 39 & 4,592 & 40 & \\
\hline 20 & 1,759 & 18 & & 40 & 3,745 & 73 & \\
\hline
\end{tabular}

* Identifies normal sera with anti-Ro/SSA binding over 4,800 U inhibited by $>50 \%$ with $10 \mu \mathrm{g} / \mathrm{ml}$ Ro/SSA. $\log _{10}$ averages of 3 to 9 separate determinations are presented. 


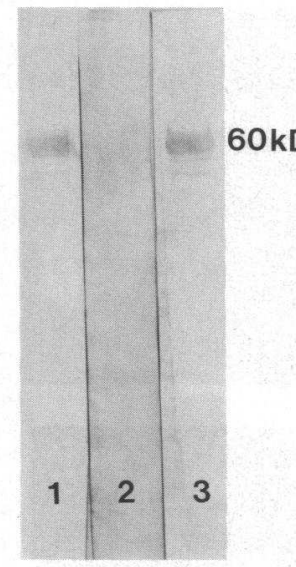

Figure 1. Western blot of purified Ro/SSA using SLE serum in lane 1 , normal serum (No. 11) in lane 2, and normal serum (No. 37) in lane 3. SLE serum and normal serum No. 37 both identify the 60,000-mol-wt Ro/SSA polypeptide while normal serum No. 11 does not.

(17.5\%) consistently had the highest binding activity, which was inhibited by $>50 \%$ with purified bovine Ro/SSA in competition assays. These seven sera were carefully evaluated to determine if this apparent antibody binding activity was Ro/SSA specific or due to nonspecific binding.

Human Ro/SSA was purified and used for inhibition experiments to establish whether or not the binding was potentially a true autoantibody as opposed to a heteroantibody against bovine Ro/SSA (Table II). Each of the high binding sera that were inhibited by bovine Ro/SSA were also inhibited by $>50 \%$ with the human antigen.
Table III. Anti-Ro/SSA Binding Activity in Serum and $F\left(a b^{\prime}\right)_{2}$ Fragments of Normal Donors

\begin{tabular}{|c|c|c|c|c|c|}
\hline \multirow[b]{2}{*}{ Sera } & \multirow[b]{2}{*}{$\begin{array}{l}\text { Donor } \\
\text { No. }\end{array}$} & \multicolumn{2}{|l|}{ Whole serum } & \multicolumn{2}{|c|}{$\mathrm{F}(\mathrm{ab})_{2}$ fragments } \\
\hline & & $\begin{array}{l}\text { Specific } \\
\text { binding }\end{array}$ & $\begin{array}{l}\text { Inhi- } \\
\text { bition }\end{array}$ & $\begin{array}{l}\text { Specific } \\
\text { binding }\end{array}$ & $\begin{array}{l}\text { Inhi- } \\
\text { bition }\end{array}$ \\
\hline & & & \% & & $\%$ \\
\hline $\begin{array}{l}\text { Patient sera with } \\
\text { anti-Ro/SSA } \\
\text { precipitin }\end{array}$ & & $14,808,000$ & 99 & $17,622,000$ & 99 \\
\hline Normal sera & 4 & 16,686 & 54 & 20,711 & 71 \\
\hline with elevated & 14 & 6,547 & 52 & 4,043 & 38 \\
\hline anti-Ro/SSA & 21 & 17,095 & 81 & 11,985 & 51 \\
\hline \multirow[t]{2}{*}{ activity } & 25 & 23,690 & 85 & 49,946 & 68 \\
\hline & 37 & 5,524 & 54 & 8,154 & 64 \\
\hline Normal sera & 11 & 1,117 & 37 & 1,336 & 13 \\
\hline with low & 13 & 664 & 29 & 850 & 12 \\
\hline anti-Ro/SSA & 27 & 1,041 & 30 & 1,939 & 27 \\
\hline \multirow[t]{3}{*}{ activity } & 28 & 1,029 & 41 & 2,800 & 35 \\
\hline & 31 & 1,357 & 41 & 1,455 & 10 \\
\hline & 35 & 587 & 19 & 4,037 & 39 \\
\hline
\end{tabular}

$\mathrm{F}(\mathrm{ab})_{2}$ fragments were purified from IgG of 1 patient and 11 normal donors, and tested by ELISA for anti-Ro/SSA activity. Four of the five normal sera with elevated anti-Ro/SSA demonstrated binding due to the $F(a b)_{2}$ fragments of IgG.

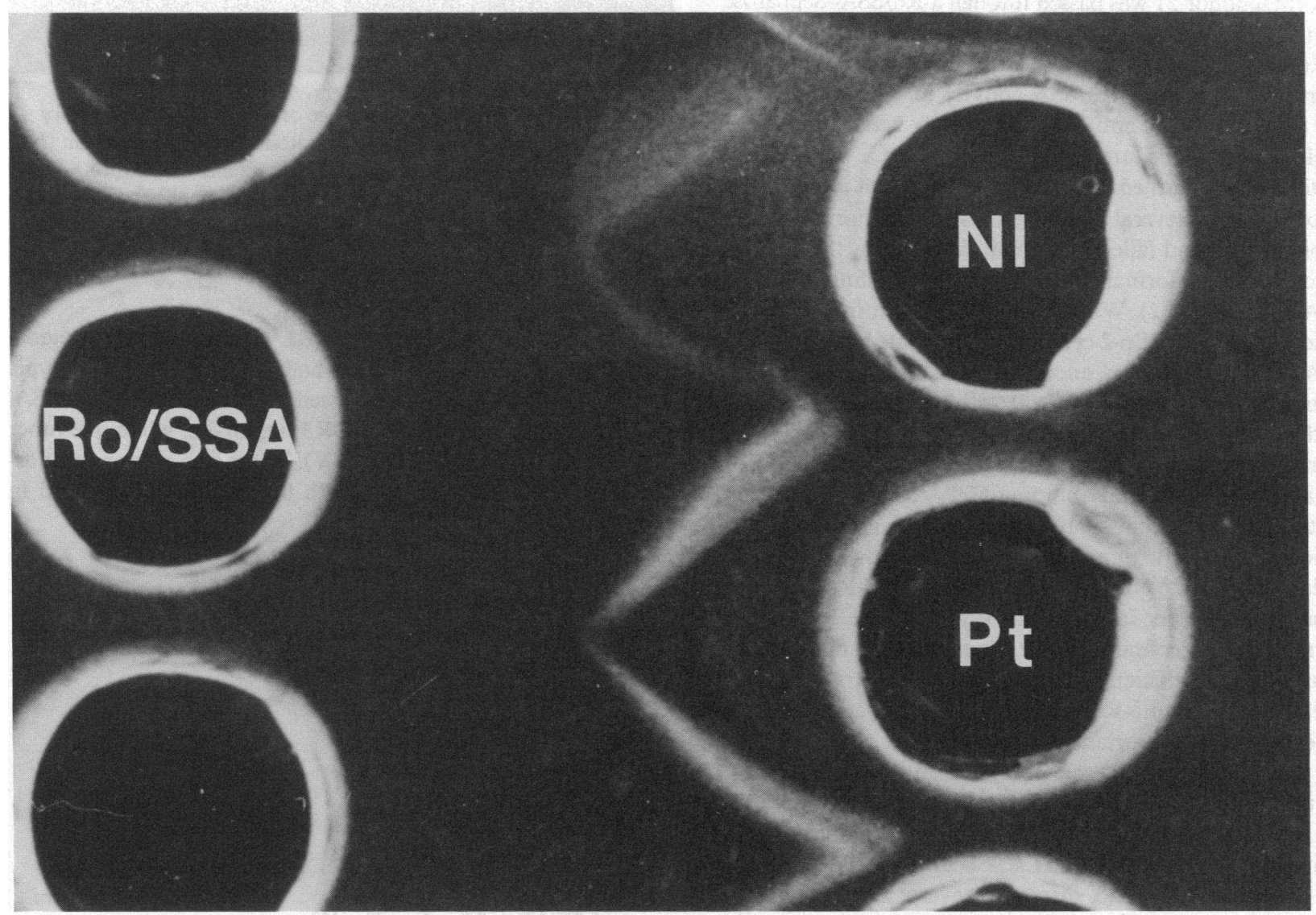

Figure 2. CIE of affinity-purified anti-Ro/SSA from a normal donor (NI) and an autoimmune patient serum with high levels of anti-Ro/SSA (Pt). Both precipitate purified Ro/SSA antigen (Ro/SSA). 
Several of the normal sera were tested by Western blot to demonstrate binding to the 60,000 -mol-wt antigenic Ro/SSA protein. Fig. 1 shows the binding of an anti-Ro/SSA-positive patient in lane 1 , an anti-Ro/SSA-negative normal serum in lane 2 (donor 11), and a normal with elevated anti-Ro/SSA by ELISA in lane 3 (donor 37). The patient and donor 37 sera both bound the 60,000-D Ro/SSA polypeptide.

Sera from 13 of the normal donors were reassessed for antiRo/SSA activity after $18 \mathrm{mo}$. Five of the seven control sera with high anti-Ro/SSA continued to display elevated binding activity, while sera from two normal donors no longer bound Ro/SSA. Six of the normal controls that previously failed to bind Ro/ SSA remained negative.

To determine whether the antigen-combining portion of $\mathrm{IgG}$ was binding Ro/SSA, $\mathrm{F}\left(\mathrm{ab}^{\prime}\right)_{2}$ fragments were prepared from normal sera, of which five bound Ro/SSA and six did not. Also included was one Ro/SSA precipitin-positive patient serum. Table III shows anti-Ro/SSA activity by ELISA due to purified $\mathrm{F}\left(\mathrm{ab}^{\prime}\right)_{2}$ compared with the anti-Ro/SSA activity in whole serum. Four sera had anti-Ro/SSA activity attributable to the $F\left(a^{\prime}\right)_{2}$ segment of IgG that could be blocked by purified Ro/SSA in competition assays. Donor serum No. 14 failed to satisfy criteria for specific reactivity in the $F\left(a^{\prime}\right)_{2}$ serum fraction and was not significantly different from the negative control group. Either this serum did not have specific binding when originally tested or the antibody binding was destroyed by pepsin digestion. Indeed, its whole serum reactivity only marginally satisfied the arbitrary criteria for binding to Ro/SSA.

To purify Ro/SSA-specific IgG from normal serum, plasma from normal donor 21 was passed through a Ro/SSA-Sepharose 4B affinity column and the bound immunoglobulin was eluted. Anti-Ro/SSA activity in the eluted Ro/SSA-specific IgG was compared with the anti-Ro/SSA activity in the donor's total IgG by ELISA. Specific anti-Ro/SSA activity was concentrated 17.7-fold by this procedure relative to whole IgG.

Anti-Ro/SSA purified from normal and patient plasma were then compared in several assay systems. While normal donor 21 whole plasma had failed to precipitate Ro/SSA, the purified anti-Ro/SSA from normal plasma precipitated affinity-purified Ro/SSA in CIE (Fig. 2). When tested by indirect immunofluorescence on cultured HEp-2 cells, the concentrated normal antiRo/SSA showed a speckled nuclear pattern similar to anti-Ro/ SSA from patient serum (Fig. 3). Relative binding affinities of purified anti-Ro/SSA from patient and normal plasma were compared in ELISA by determining the concentration of Ro/ SSA that inhibited antibody binding 50\%. Anti-Ro/SSA from precipitin-positive patient serum and normal donor 21 had virtually identical relative binding affinities, as shown in Fig. 4. The relative affinity of the patient's purified anti-Ro/SSA was identical to that of her IgG and was similar to the IgG of five other anti-Ro/SSA containing sera. Thus, we have no evidence that purified and sufficiently concentrated anti-Ro/SSA from normal plasma and anti-Ro/SSA purified from patient plasma are different in any important respect.

All normal sera were tested for additional autoantibodies, and two of the seven sera with elevated anti-Ro/SSA demonstrated further serologic abnormalities. Donor 37 was a $25-\mathrm{yr}-$ old white female who also bound La/SSB by ELISA (15). Donor 4, a 22-yr-old white female, displayed several additional links to autoimmunity, including low titer antinuclear antibody, antisingle-strand DNA, intermittently positive rheumatoid factor at
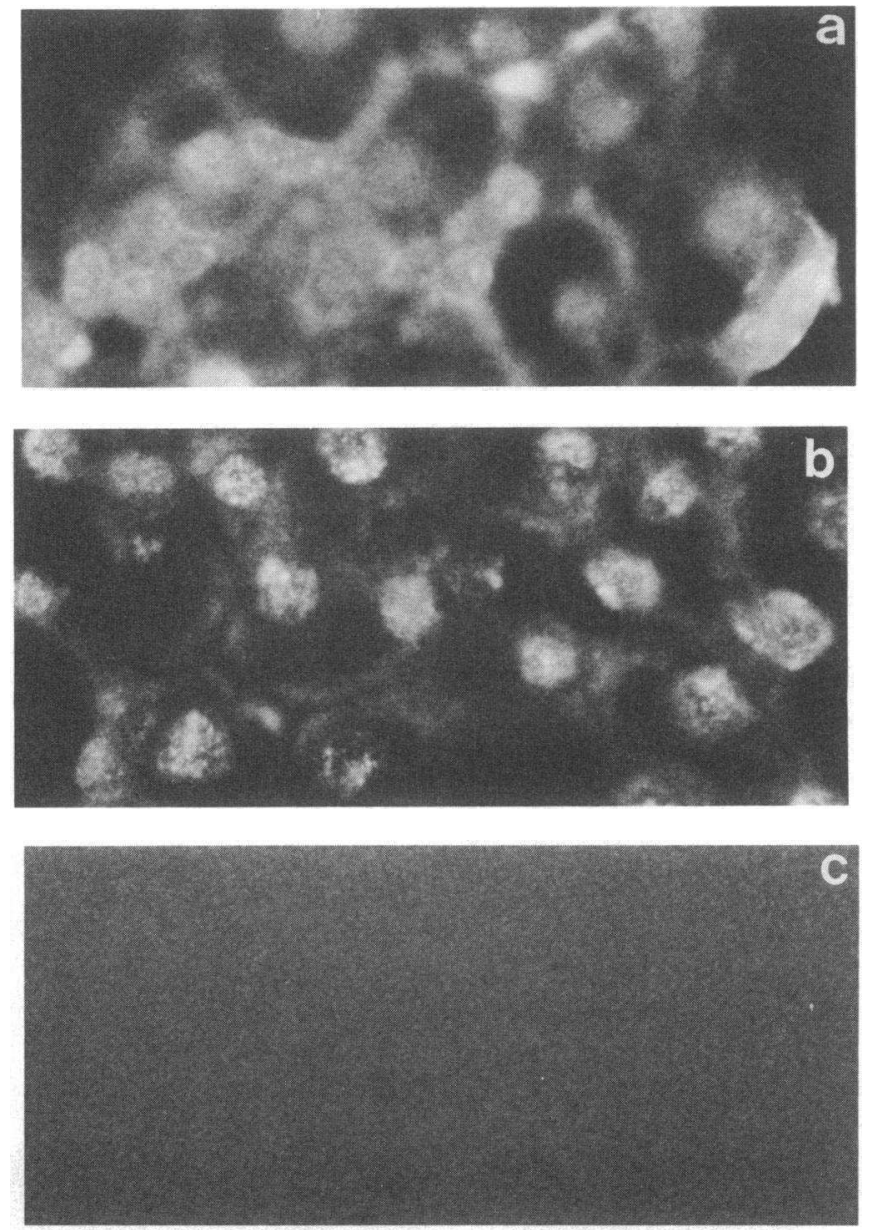

Figure 3. Indirect immunofluorescence of affinity-purified anti-Ro/ SSA from a normal donor $(a)$ and an autoimmune patient serum $(b)$ compared with a normal serum with no detectable anti-Ro/SSA activity $(c)$. Affinity-purified anti-Ro/SSA from a normal donor and an autoimmune patient both displayed a speckled nuclear binding pattern on cultured HEp-2 cells.

low titer, and a false-positive VDRL 6 mo before the original serum sampling. This individual had the HLA DR3 haplotype. Of the five normal individuals tested whose sera bound Ro/SSA, only this donor had the HLA-DR3 haplotype, while one other was HLA-DR2 positive (Table IV). There was no apparent association of an HLA antigen with the anti-Ro/SSA found in these normal sera.

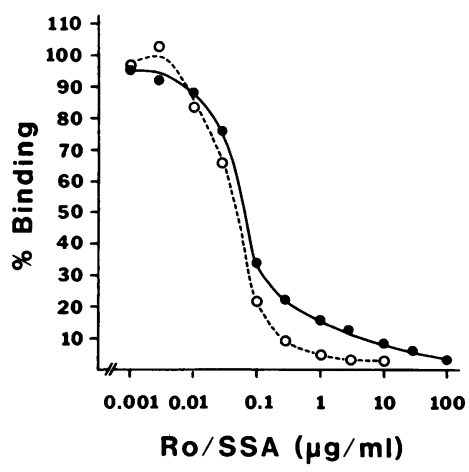

Figure 4. Relative affinity of affinity-purified anti-Ro/ SSA from a normal donor (solid circles) and from an autoimmune patient serum (open circles). 
Table IV. HLA Typing, Age, Sex, and Race of Anti-Ro/SSA-positive Normal Donors

\begin{tabular}{lccllll}
\hline Donor no. & A & B & DR & Age & Sex & Race \\
\hline 4 & 1, w32 & 8,40 & 3,4 & 22 & F & C \\
14 & 3,29 & 7, w44 & 2,7 & 25 & F & C \\
21 & $28,-^{*}$ & 44,62 & 5,8 & 41 & M & C \\
25 & 1,3 & 7,14 & $1,6 Y$ & 49 & M & C \\
37 & $2,--^{*}$ & w44, w62 & 1,4 & 25 & F & C
\end{tabular}

F, Female; M, male; and C, Caucasian.

* Indicative of homozygous alleles or a rare antigen without available typing sera.

All 40 normal sera were screened by ELISA for anti-La/ SSB and anti-nRNP(Sm) reactivity. Three sera (7.5\%) showed elevated anti-La/SSB levels, which proved to be autoantigen specific as shown previously (15). None of the 40 normal sera bound nRNP(Sm) (Fig. 5).

\section{Discussion}

We have established that certain normal individuals have elevated levels of anti-Ro/SSA autoantibody. The antibody can can be demonstrated by binding to purified Ro/SSA in a solidphase ELISA and Western immunoblot as well as precipitation in CIE after concentration. Binding in the anti-Ro/SSA ELISA was inhibited by both human and bovine Ro/SSA in competition assays. The antigen binding was found in the $F\left(a b^{\prime}\right)_{2}$ segment of IgG and therefore can not be attributed to a nonspecific $\mathrm{Fc}$ interaction. Anti-Ro/SSA IgG was concentrated 17.7-fold when purified from normal plasma by affinity chromatography.

While $17.5 \%$ of normal sera bound Ro/SSA, none of the 40 normal sera had anti-nRNP(Sm) activity. In SLE precipitating antibodies to Ro/SSA and La/SSB tend to occur together, while anti-Sm is associated with anti-nRNP (12). The finding that antiRo/SSA commonly occurs at low levels in the normal population while anti-nRNP(Sm) do not $(P=0.007$, Fisher's exact test using

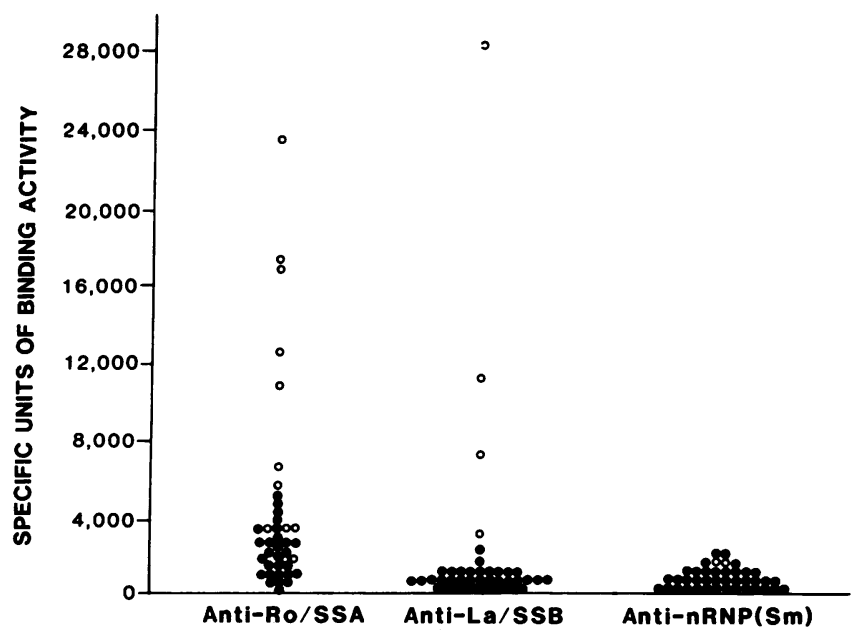

Figure 5. Specific units of anti-Ro/SSA, anti-La/SSB, and anti$\mathrm{nRNP}(\mathrm{Sm})$ binding activity in $\mathbf{4 0}$ normal sera as determined by ELISA. (Solid circles) Represent $<50 \%$ inhibition with purified antigen; (open circles) represent $>50 \%$ inhibition. data from Fig. 5) is consistent with the observed separation of these autoantibodies. This may indicate that different mechanisms of autoantibody generation are responsible for the presence of these autoantibodies in SLE. Anti-Ro/SSA and anti-La/SSB may occur in SLE by some phenomenon that enhances the production of antibody already present in some normal individuals. On the other hand, the initiation of anti-nRNP or anti-Sm would apparently require some primary immune response, as these autoantibodies are rare or absent in the normal population.

The presence of autoantibodies in low frequencies among normal subjects has been reported from time to time, including antinuclear antibodies and rheumatoid factor $(23,24)$. When autoantibodies were assessed in normal females according to age, the highest incidence occurred in the older age group (24). Less frequently precipitating levels of autoantibody to ribonuclear proteins have been documented $(9,24,25)$. The highest incidence of autoantibody in normal individuals has been reported in mothers of neonatal lupus infants. More than $80 \%$ of these asymptomatic mothers have anti-Ro/SSA and/or anti$\mathrm{La} / \mathrm{SSB}$ with no clinical manifestations of autoimmune disease $(7,8)$. These mothers, however, seem to be at risk for future development of the clinical symptoms of connective tissue disease (26). With the application of solid-phase assays for more sensitive detection of autoantibodies to Ro/SSA, La/SSB, nRNP, and $\mathrm{Sm}$, it may be possible to better identify another population of normals at risk for developing autoimmune disease. This would be especially relevant in the case of donor 4 , who had the HLA B8, DR3 haplotype associated with increased risk of developing SLE (27), and had been associated with anti-Ro/SSA precipitins in lupus (28).

An increased prevalence of SLE in females over males has been documented (29), as well as an increase in autoreactivity among the elderly (24). 24 females and 16 males participated in this study, which is equal to the ratio of anti-Ro/SSA-positive females and males, 3:2 (Table IV). When the average age of our normal donors was assessed, the anti-Ro/SSA-positive donor's mean age was $32.4 \mathrm{yr}$, which was not significantly different from the group average of $32.7 \mathrm{yr}$. Thus, in our study, neither sex nor age accounted for the high incidence of Ro/SSA binding in the normal sera. When the mean ages of anti-Ro/SSA-positive females versus males were considered, however, the average female age was $24 \mathrm{yr}$, compared with the average age of males, which was $45 \mathrm{yr}$. This becomes interesting in light of the observation that the largest proportion of female SLE patients have disease onset at a young age (29).

Low levels of autoanti-Ro/SSA in normal donor plasma, similar to patient anti-Ro/SSA in binding characteristics, establishes the presence of autoreactive B cell clones in the repertoire of normal individuals. Recently there have been other reports of autoreactive immunoglobulin-secreting cells in normals. Hoch and Schwaber have shown that human hybridomas from splenic lymphocytes of a nonautoimmune individual secrete anti-DNA antibodies equivalent to those derived from SLE patients (30). Mumford et al. detected antibodies to $\mathrm{La} / \mathrm{SSB}, \mathrm{RNP} / \mathrm{Sm}$, and DNA in supernatant cultures from peripheral blood lymphocytes of healthy controls (31), which confirms the results of Mach et al., who reported anti-DNA antibodies produced by normal peripheral blood mononuclear cells (32). These findings all support the hypothesis that autoreactive cells are controlled by suppression rather than clonal deletion. The transition from a normal state to the expression of disease may then occur by loss of $\mathrm{T}$ 
cell suppressor function, which results in activation and expansion of autoreactive clones under the appropriate stimulus.

\section{Acknowledgments}

The authors are grateful for the assistance of Dr. Richard Hyde, Judy Alcott, and Charles O'Brien.

This study was supported by National Institutes of Health grants AM-34159, AM-31133, and AI-25168, the Veterans Administration, Oklahoma Lupus Association, Inc., a Basil O'Connor Starter Grant (5507) from the March of Dimes Birth Defects Foundation, and an Arthritis Center Grant from the Arthritis Foundation. J. B. Harley is an investigator of the Arthritis Foundation. K. K. Gaither was a recipient of a Gina Finza Memorial Summer Fellowship from the Lupus Foundation of America.

\section{References}

1. Clark, G., M. Reichlin, and T. B. Tomasi. 1969. Characterization of a soluble cytoplasmic antigen reactive with sera from patients with systemic lupus erythematosus. J. Immunol. 102:117-122.

2. Alspaugh, M. A., and E. M. Tan. 1975. Antibodies to cellular antigens in Sjögren's syndrome. J. Clin. Invest. 55:1067-1073.

3. Harley, J. B., E. L. Alexander, W. B. Bias, O. F. Fox, T. T. Provost, M. Reichlin, H. Yamagata, and F. C. Arnett. 1986. Anti-Ro(SSA) and anti-La(SSB) in patients with Sjögren's syndrome. Arthritis Rheum. 29: 196-206.

4. Wasicek, C. A., and M. Reichlin. 1982. Clinical and serological differences between systemic lupus erythematosus patients with antibodies to Ro versus patients antibodies to Ro and La. J. Clin. Invest. 69:835843.

5. Provost, T., F. Arnett, and M. Reichlin. 1983. Homozygous C2 deficiency, lupus erythematosus, and anti-Ro(SSA) antibodies. Arthritis Rheum. 26:1279-1281.

6. Maddison, P. J., T. T. Provost, and M. Reichlin. 1981. Serological findings in patients with "ANA-negative" SLE. Medicine (Baltimore). 60:87-94.

7. Scott, J., P. Maddison, P. Taylor, E. Esscher, O. Scott, and P. Skinner. 1983. Connective tissue disease, antibodies to ribonucleoprotein, and congenital heart block. N. Engl. J. Med. 309:209-212.

8. Kephart, D. C., A. F. Hood, and T. T. Provost. 1981. Neonatal lupus erythematosus: new serologic findings. J. Invest. Dermatol. 77: 331-333.

9. Maddison, P., H. Mogavero, T. Provost, and M. Reichlin. 1979. The clinical significance of autoantibodies to a soluble cytoplasmic antigen in systemic lupus erythematosus and other connective tissue diseases. $J$. Rheumatol. 6:189-195.

10. Pereira, R. S., and P. J. Maddison. 1985. Antinuclear antibodies in the families of patients with systemic sclerosis. Arthritis Rheum. 28: S84. (Abstr.)

11. Lehman, T. J., V. Hanson, N. Zvaifler, G. Sharp, and M. Alspaugh. 1984. Antibodies to non-histone nuclear antigens and antilymphocyte antibodies among children and adults with systemic lupus erythematosus and their relatives. J. Rheumatol. 11:644-647.

12. Wolin, S. L., and J. A. Steitz. 1984. The Ro small cytoplasmic ribonucleoproteins: identification of the antigenic protein binding site on the Ro RNAs. Proc. Natl. Acad. Sci. USA. 81:1996-2000.

13. Reichlin, M., and M. Mattioli. 1974. Antigens and antibodies characteristic of systemic lupus erythematosus. Bull. Rheum. Dis. 24: 756-760.

14. Yamagata, H., J. B. Harley, and M. Reichlin. 1984. Molecular properties of the Ro/SSA antigen and enzyme-linked immunosorbent assay for quantitation of antibody. J. Clin. Invest. 74:625-633.

15. Hendrick, J. P., S. L. Wolin, J. Rinke, M. R. Lerner, and J. A. Steitz. 1981. Ro small cytoplasmic ribonucleoproteins are a subclass of $\mathrm{La}$ ribonucleoproteins: further characterization of the Ro and La small ribonucleoproteins from uninfected mammalian cells. Mol. Cell. Biol. 1:1138-1149.

16. Harmon, C. E., J. Deng, C. L. Peebles, and E. M. Tan. 1984. The importance of tissue substrate in the SS-A/Ro antigen-antibody system. Arthritis Rheum. 27:166-173.

17. Harley, J. B., H. Yamagata, and M. Reichlin. 1984. Anti-Ro/ SSA antibody is present in some normal sera and is coincident with antiRo/SSA precipitins in systemic lupus erythematosis. J. Rheumatol. 11: 309-314.

18. Gaither, K. K., and J. B. Harley. 1985. Affinity purification and immunoassay of anti-Ro/SSA. Protides Biol. Fluids Proc. Collog. 33: 413-416.

19. Towbin, H., T. Staehelin, and J. Gordon. 1979. Electrophoretic transfer of proteins from polyacrylamide gels to nitrocellulose sheets: procedure and some application. Proc. Natl. Acad. Sci. USA. 76:43504354.

20. Dow, M. L. 1985. An improved method of antigen detection on nitrocellulose by in situ staining of alkaline phosphatase conjugated antibody. J. Immunol. Methods. 82:225-231.

21. Garvey, J., N. Cremer, and D. Sussdorf. 1977. Subunits of IgG. In Methods in Immunology. 3rd ed. Benjamin/Cummings Publishing Co., Reading, MA. 31:256-266.

22. Chubick, A., R. D. Sontheimer, J. N. Gilliam, and M. Ziff. 1978. An appraisal of tests for native DNA antibodies in connective tissue diseases: Clinical usefulness of Crithidia lucilia assay. Ann. Intern. Med. 89:186-192.

23. Hawkins, B. R., K. J. O'Connor, R. L. Dawkins, B. Dawkins, and B. Rodgers. 1979. Autoantibodies in an Australian population. I. Prevalence and persistence. J. Clin. Lab. Immunol. 2:211-215.

24. Fritzler, M. J., J. D. Pauls, T. D. Kinsella, and T. J. Bowen. 1985. Antinuclear, anticytoplasmic and anti-Sjögren's syndrome antigenA (SSA/Ro) antibodies in female blood donors. Clin. Immunol. Immunopathol. 36:120-128.

25. Venables, P. J., P. J. Charles, R. R. Buchanan, T. Yi, P. A. Mumford, L. Schrieber, G. R. Room, and R. N. Maini. 1983. Quantitation and detection of isotypes of anti-SSB antibodies by ELISA and Farr Assays using affinity purified antigens. Arthritis Rheum. 26:146155.

26. Esscher, E., and J. S. Scott. 1979. Congenital heart block and maternal systemic lupus erythematosus. Br. Med. J. 1:1235-1238.

27. Tiwari, J. L., and P. I. Terasaki. 1985. Connective tissue diseases. HLA and Disease Association. Springer-Verlag, New York. 16:363-369.

28. Bell, D. A., and P. J. Maddison. 1980. Serologic subsets in systemic lupus erythematosus. Arthritis Rheum. 23:1268-1273.

29. Masi, A. T., and R. A. Kaslow. 1978. Sex effects in systemic lupus erythematosus: a clue to pathogenesis. Arthritis Rheum. 21:480484.

30. Hoch, S., and J. Schwaber. 1986. Specificity analysis of human anti-DNA antibodies. J. Immunol. 136:892-897.

31. Mumford, P., G. R. W. Room, P. J. W. Venables, and R. N. Maini. 1985. IgG antibodies to SS-B(La), RNP/Sm and DNA are produced by PWM-stimulated normal human lymphocytes in culture. Rheumatol. Int. 5:109-112.

32. Mach, P. S., M. Kharouby, F. Luycher, J. L. Olivier, N. Bozely, M. Dougados, and B. Amor. 1984. The in vitro production and regulation of anti double stranded DNA antibodies by peripheral blood mononuclear cells from normals and patients with systemic lupus erythematosus. Clin. Exp. Immunol. 57:338-344. 